\title{
8
}
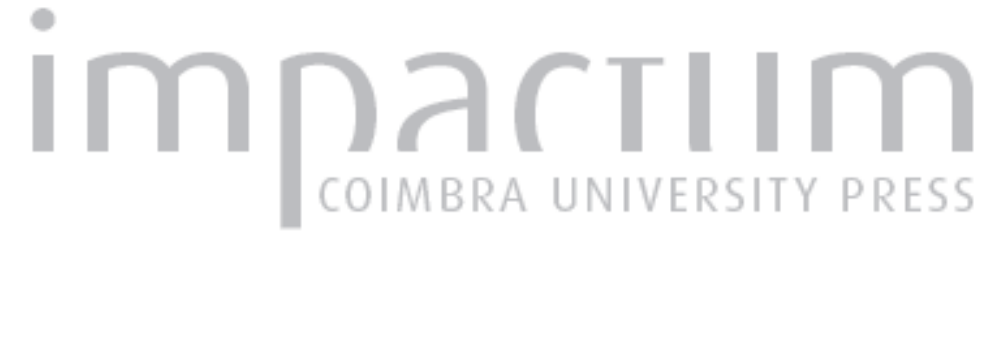

\section{Still life, duração e abandono na obra de John Hejduk}

Autor(es): $\quad$ Ferreira, Francisco

Publicado por: Editorial do Departamento de Arquitectura

URL persistente:

URI:http://hdl.handle.net/10316.2/37486

DOI:

DOI:http://dx.doi.org/10.14195/0874-6168_5_6

Accessed : $\quad$ 26-Apr-2023 15:54:05

A navegação consulta e descarregamento dos títulos inseridos nas Bibliotecas Digitais UC Digitalis, UC Pombalina e UC Impactum, pressupõem a aceitação plena e sem reservas dos Termos e Condições de Uso destas Bibliotecas Digitais, disponíveis em https://digitalis.uc.pt/pt-pt/termos.

Conforme exposto nos referidos Termos e Condições de Uso, o descarregamento de títulos de acesso restrito requer uma licença válida de autorização devendo o utilizador aceder ao(s) documento(s) a partir de um endereço de IP da instituição detentora da supramencionada licença.

Ao utilizador é apenas permitido o descarregamento para uso pessoal, pelo que o emprego do(s) título(s) descarregado(s) para outro fim, designadamente comercial, carece de autorização do respetivo autor ou editor da obra.

Na medida em que todas as obras da UC Digitalis se encontram protegidas pelo Código do Direito de Autor e Direitos Conexos e demais legislação aplicável, toda a cópia, parcial ou total, deste documento, nos casos em que é legalmente admitida, deverá conter ou fazer-se acompanhar por este aviso.

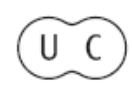




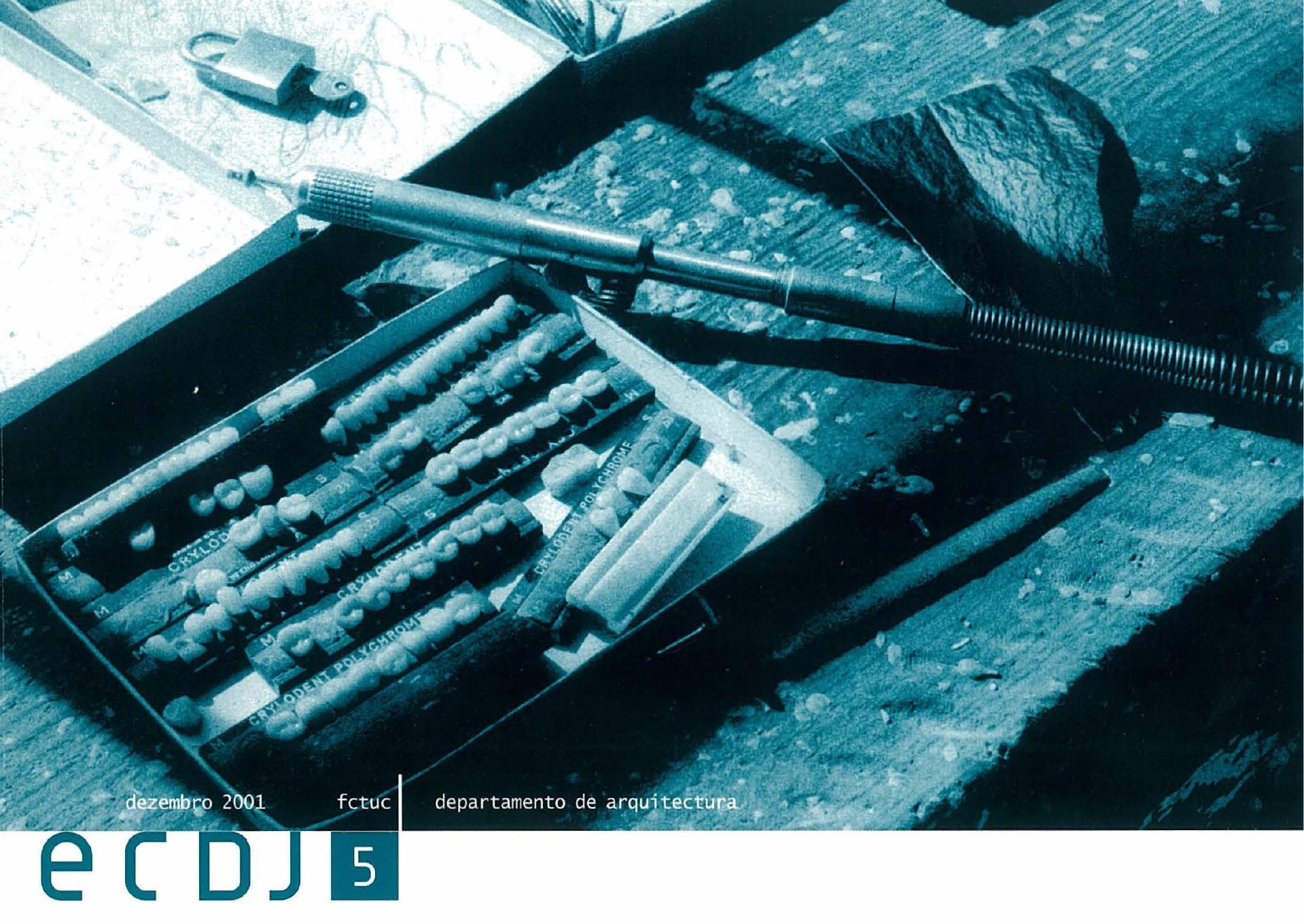

\section{investigação em arquitectura [?]}

George Teyssot

Paulo Providência | Mário Krüger | Wałter Rossa | António olaio

Outra abertura adelino gonçałves

Sti11Life, duração e abandono na obra de john hejduk francisco ferreira

Onde há fogo, nós levamos gasolina pedro bandeira

Apontamentos sobre a arquitectura religiosa do séc. XX em Portugal cidália silva

o desafio ecológico luís pinto faria

Pescada de rabo na boca patrícia miguel carvalho

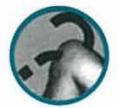




\section{$\left\{\begin{array}{l}\text { texto francisco ferreira } \\ \text { Sti11Life, Duração e Abandono }\end{array}\right.$ na Obra de John Hejduk}

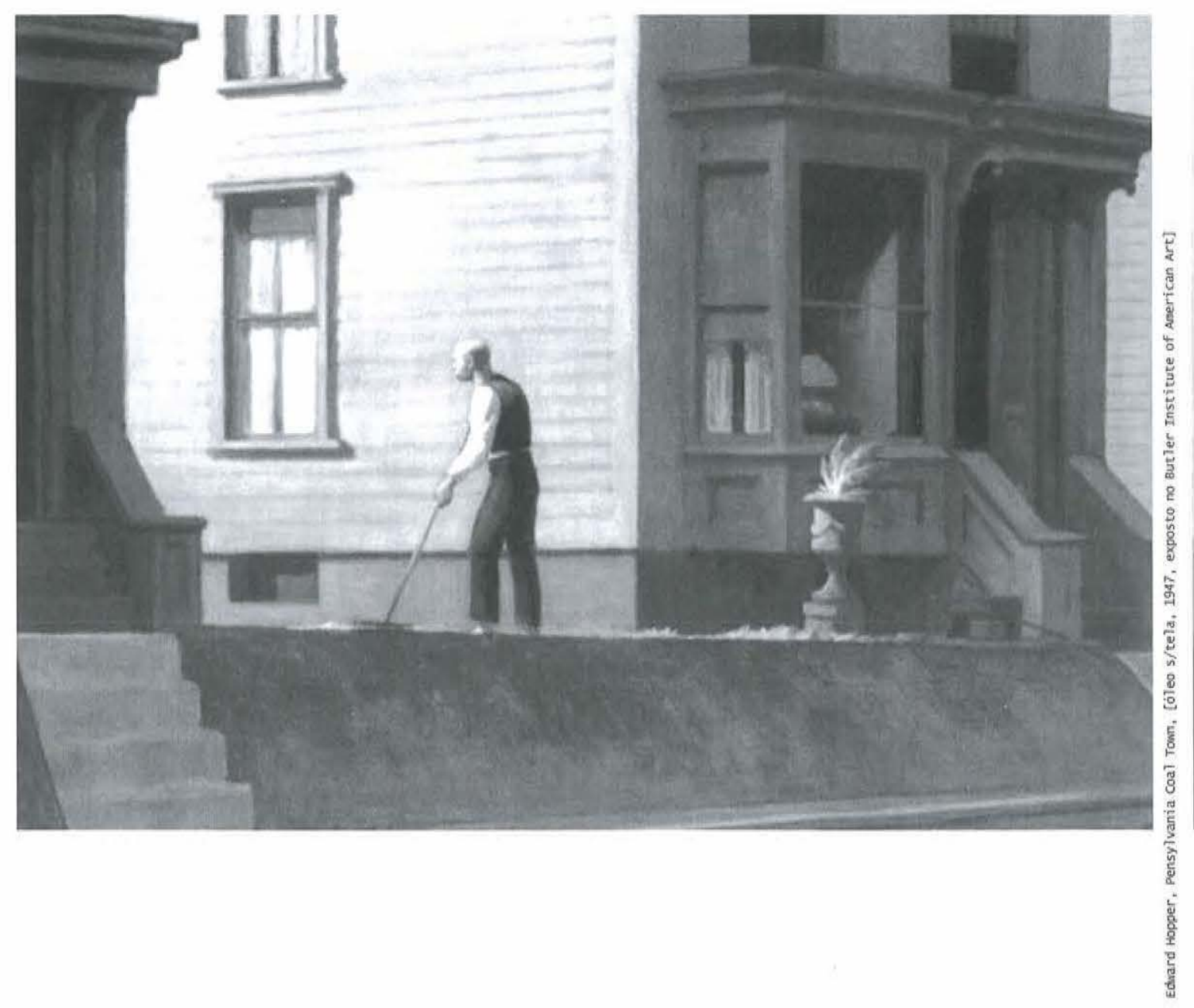


"Somehow our own relation to specific events and images in time appears to be focused upon certain haunting disparate fragments of our experience, we are both observer and participator as in a game of billiards" John Hejduk, in Cable from Milan

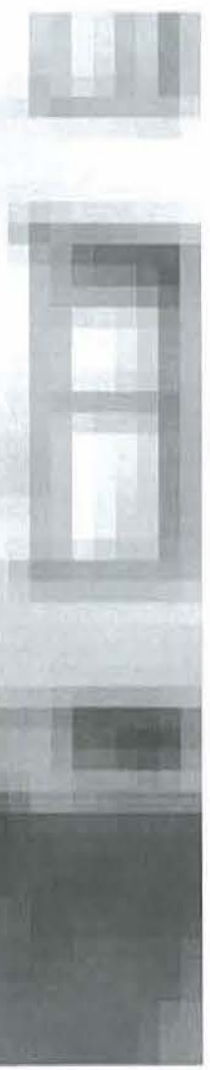

> Sabemos como a modernidade se impôs ao percurso anónimo do tempo, fazendo-o ganhar consciência de si na composiçăo que do presente, segundo uma vocação de futuro, fez, alicerçando a sua construção numa ideia consciente de progresso, donde acabaria por resultar a emancipação como conceito racionalmente sagrado para o desenvolvimento e evolução da existência em sociedade. A modernidade corporeizou-se assim como um desejo de constante superação, reflexo do pensamento racional que, consciente da sua autónoma existência, se dedica à sistematizaçăo da evoluçăo como único modo de operar na definiçăo de uma lógica tempora1.

Ao correr do tempo como sentido de que o indivíduo se apodera para fundamentar a sua auto-superaçăo, Aldo Rossi opôs outra concepçăo, de um tempo como atmosfera e cronologia, elemento etéreo e ininterrupto de mediçăo que, inversamente, nos ocupa e envolve, conduzindo e incluindo numa suave continuidade, as acções que vamos levando a cabo ["E] doble significado, atmosférico y cronológico del tiempo, es el princípio que preside a toda construcción"]. (1) De facto, a análise tipológica que Rossi levou a cabo como investigação científica para o controlo e sustentação do espaço urbano, apoiava-se na convicçăo de que o espaço mimetiza o tempo, no sentido de se constituir como (infra)estrutura de uma acção que não determina a tipologia pelas suas variadas formas, apenas a habitando, como essência ou justificação. Por isso a ideia de rito é tăo cara a Rossi, pois eterniza uma repetição, conferindo-The qualidades já não de acontecimento, mas de fundo ou 
cenário ["Siempre he afirmado que los 7ugares son más fuertes que Tas personas, el escenario más que el acontecimiento"].(2) Assim, para Aldo Rossi, o tipo inclui-se na narrativa de qualquer espaço urbano, querendo mantê-1a viva e perene. Arquitectura como rito, mais do que acto criativo, afirmava o autor, arquitectura como confortável repetiçăo que se perde no passado e configura já o futuro.

> De outro modo, John Hejduk ritualiza as suas acçốes como segmentos de uma narrativa que está sempre presente na obra como procura de uma obscura totalidade que se pretende nomear através dos valores de autenticidade que reconhece e articula nas formas, elementos arquétipos que transporta na sua memória como impressőes, aos quais não se inibe de atribuir novos significados. Assim, por oposição a Rossi, em Hejduk o tipo, paradoxalmente, não significa uniformização ou suporte, mas acontecimento; como acção ou performance não é estrutural ou organizativo, mas experimental e metamorfoseante. A ideia de rito é assim interpretada por Hejduk como vazia manifestação de eternidade, redundância que, aliada à certeza da morte, requestiona a oposição entre 1inearidade e circularidade temporal, continuidade e devir, suspendendo o presente num espaço sem sulcos ou sentidos pré-definidos. Anacronia versus diacronia, portanto, considerando que, através da ausência de medida, o tempo assume qualidades espaciais macias, (3) onde a acção se desenrola, não por consequência, mas por descontextualizada paixão. Se para Rossi, a máquina da arquitectura é uma máquina do tempo, configurada como testemunho ininterrupto de uma nostalgia convertida em edificaçăo, nas propostas de Hejduk habita uma melancolia operativa que transforma esse testemunho em participação do presente. Seguindo a definiçăo de Rossi a máquina da arquitectura assume-se na obra de Hejduk como máquina de tempo anacrónico, que funciona através de múltiplas conexőes a muitas outras máquinas, que, na essência da sua multiplicidade, determinam o tempo como incógnito acontecer.

A ideia de rito é assim interpretada por Hejduk como vazia manifestação de eternidade. 
> LEm The collapse of Time, John Hejduk ensaia uma concepção de oposição à condição do tempo de cadenciado colapso, ou cronofagia disfarçada de intocável presença. No texto que acompanha a proposta, única voz de um projecto que, silenciosamente, se revela como construçăo paradoxal de uma suspensão determinada por distintos movimentos, Hejduk afirma a sua inquietação pela imperceptibilidade do presente, que, segundo escreve, é opaco, branqueando o tempo ["One of my recurrent persistences is that present time cannot be seen...present time has an opacity...present time is opaque...present time erases...blanks out time..."] (4) Partindo da análise de uma série de brochuras de cidades italinas que acabara de receber, Hejduk imagina um périplo pelos lugares aí retratados onde tempo e espaço, reunidos num ritual que articula quietude e movimento, se expressam como peças de uma engrenagem construída a partir da impossível ideia de captura duradoura do presente. [The Italian booklets I held in my hands had the effect of drying the moisture on my skin. (...)Their contents seemed to be making a request, but I was not quite sure. Surely they were the private places of an architect's sou 1.... (5)

$>0$ objecto, totalmente construído em madeira e apoiado num conjunto de rodas metálicas, é composto por uma coluna de cubos de madeira, que preenche, em posição horizontal, uma caixa definida pelos tramos da sua própria estrutura; fixos a essa estrutura, dois elementos semi-circulares paralelos entre si, servem de guia ao movimento que será efectuado pela torre. Assente em dois carris de ferro, o objecto anuncia, à priori, um caminho pré-definido [The clock tower on the caisson can be moved from place to place... from time to time... The clock will be used in my conversation on time with the north of Italy.] (6) Uma sucessão de algarismos, do 1 ao 13 , percorre, em sentido ascendente, os cubos que formam a torre, sobre os quais desliza uma fina superfície de forma quadrada, destinada a quantificar - apagando - o tempo. Acompanhando o deslizamento da superfície sobre os algarismos, o movimento da torre assume três posiçőes determinantes: a posição inicial, vertical, a $90^{\circ}$ (flat time), uma posiçăo intermédia, a $45^{\circ}$ (isometric time) e finalmente, a posição horizontal, a $0^{\circ}$, recolhida na caixa (past time). Entretanto, um homem eleito entre a população da cidade em que se desenrola a acção, sentado numa cadeira suspensa num poste colocado em posiçăo frontal ao edifício-relógio, acompanha, num movimento descendente, os vários estádios de posição da torre, encontrando o chão no momento em que aquela encontra a posição horizontal. Em simultâneo, ainda, uma mulher - igualmente eleita encerrada numa cabina pertencente ao conjunto de objectos que compōem a cena, Tê continuamente, durante o período de 24 horas que dura a acção, o poema The sleep of Adam - "While Eve waited/inside of Adam/she was his structure/her volume/filled him/his skin hung/on Eve's form/when God/released her/from Adam/Death rushed in/preventing collapse". Em tensa 
relaçäo com a cena, Security - estrutura resgatada de victims (7) permanece, imóvel e ambígua no seu exterior. No final, homem e mulher, como paradigmas do mito da criação e portanto objectos centrais de um retorno cinicamente inocente à origem, após terem dependurado no poste a brochura correspondente à cidade em que se encontram, abandonam o 7ugar; às restantes pessoas, presentes durante todo o processo, cabe a responsabilidade de deslocar o edifício-relógio, a cabina e security, para outra cidade onde o ritual deverá ser reiniciado.

> A escala do edifício, destinada a um espaço exterior (público), a sua forma (quando a torre se encontra na posiçăo vertica1), próxima de um qualquer relógio de parede de um espaço interior (privado) e a sua qualidade de objecto portátil (autónomo), fazem com que o edifício-relógio assuma um significado tripartido, representando de uma só vez o tempo como elemento universal, monumentalizado, o tempo como medida institucional, segmentado, codificado, e o tempo como sujeito interno de orientação, submetido a uma cadência desigual na determinação do vivido por qualquer individuo. A posição recolhida da torre, no entanto, sugere outra Teitura; na introdução a The collapse of Time, David Shapiro refere, a propósito de um volume sobre horologia de Douglas $\mathrm{H}$. Shaffer, o facto de as caixas dos altos relógios de parede do connecticut serem frequentemente construídas por quem executava os caixöes para os mortos. Shapiro determina assim o carácter elegíaco da obra, que funciona assim como denúncia de uma época que só reconhece no tempo qualidades expansivas e não intensivas. o poema lido pela mulher na cabina representa essa intensidade, palavra sobre palavra, círculo sobre círculo, na esperança de Tibertaçäo do presente do seu espartitho de invisibilidade. Assim, o edifício-relógio, antes monumento de uma memória colectiva, segundo David Shapiro, encerra na sua horizontalidade uma condição, senảo de morte, de letargia ou ocultação de um presente que já nảo existe ou que nunca terá existido, aparecendo então como metáfora de um tempo que, afinal, mais do que atmosfera, se assume como a imagem móvel da eternidade(8).

o final, homem e mulher, como paradigmas do mito da criação e portanto objectos centrais de um retorno cinicamente inocente à origem. 
> Past time significa então a suspensão da mobilidade dessa imagem, elogio volumétrico à linha do tempo que, por momentos, se havia revelado como superfície onde cristalizar o presente. o que parece então estar em causa, neste estranho ritual proposto por Hejduk, é uma ideia de duraçăo, em que a experiência temporal se constrói segundo uma oposição entre repetição (a leitura do poema) e continuidade (o desenvolvimento paralelo do duplo movimento cadeira/homem e torre), finalizada com o abandono, por parte de todos os intervenientes, do espaço onde ocorreu. Trata-se então de uma espacialização da duraçăo, da fixação do presente năo como ponto imperceptíve 1 mas como segmento que transcende o instante, possibilitando assim a apreensão da sua presença. o presente que é ocultado pela placa que percorre os números apostos na torre aparece, no exterior dessa ocultação, como metáfora de breve mas significativa permanência. o tempo, constrói-se assim por movimentos distintos a velocidades diferentes que resultam, afina1, numa rigorosa sincronia. E depois, o abandono.

$>\mathrm{Em}$ The Collapse of Time, Hejduk suspende o texto no momento em que refere a chegada das estruturas que compõem a obra a veneza - "When a11 ten nameplaces have been visited, the structures wil1 be brought into piazza San

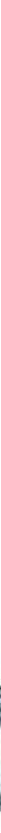


> Marco, venice, where they will be..." (9) Haverá relutância no uso da palavra, com medo, talvez, de que o nomear identifique a acção de tal modo, que o abandono nunca exista na obrigatória condiçăo de silêncio sobre o que se deixa ficar para trás? Só através da ausência da nomeação do acto terá entăo - acto verdadeira espessura, compondo-se como real melancolia sobre a condição fragmentária do sujeito e, consequentemente, da memória, que, de um carácter colectivo passa a ausente realidade. o suspender do texto é também o suspender do ritual, o abandono da acçăo, e portanto da visualização do presente como fixaçăo da memória, como única forma de identificar a experiência com a sua própria imagem; ficam apenas os objectos que a incorporaram, que, maquinalmente, a materializaram no espaço como decomposta realidade. Tempo e memória entrelaçados, peças complementares de uma mesma engrenagem. A Piazza San Marco em veneza assume-se como receptáculo deste abandono, possibilitando a dolorosa visibilidade da ausência, de um vazio sobre fundo eterno.

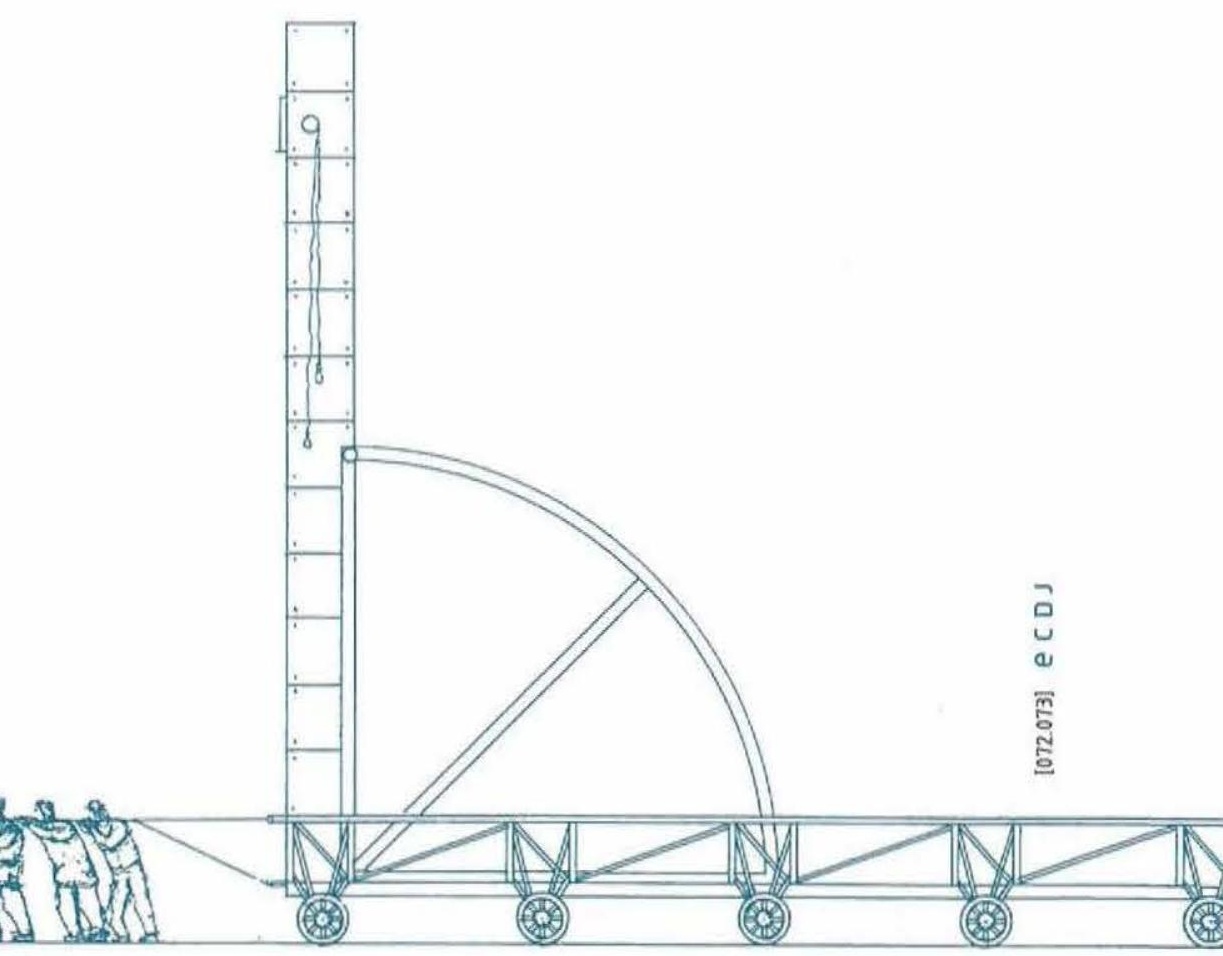


2_Em New Town for the New orthodox, John Hejduk debruça-se sobre a tota7idade da cidade, transformando-a numa composição entre o vórtice do tempo e o objecto arquitectónico como símbolo de um abandono dirigido a um destino que está sempre em primeiro plano. ["The New Town for the New orthodox is the first piece of urban planning I've ever done in my life. It was a town origina11y for 36,000 inhabitants and then I cut it back to 18,000 inhabitants. It's outside of venice, in the water. There are a whole series of canals 7ike in venice. You can see water, quay and then the house, court, house, quay and cana1. It's a11 vertica1, a11 the 1ittle houses are wa11 houses, minimal wa11 houses, a11 put together so there are some 18,000 houses. Then a huge canal and a market. The Town Market. A Town Customs which is the entry town and the Town orthodox, which contains one of the town houses. The Town House is put into the large building. There is a Town Hospital and the Town Cemetery and the Town Park. Also a Town Hotel. (...) The cemetery is 1ike a triangular section. In plan it is made up of 18,000 three by six foot slots. I'm doing an $X$-ray; you start burying people down in the lower level and they start filling in and the elevation keeps feeling in. The coffin is set back; each coffin is dropped in on top of each other, with a six inch space separating the coffins which are on 1ittle legs. The cemetery fills in and it contains 18,000 coffins and when they put the last coffin in the town is abandoned. That's the New Town for The New orthodox."] (10) Cidade flutuante, a New Town for the New orthodox constituise assim como espaço de passagem por um tempo com duração 1imitada, incapaz face à morte dos seus habitantes. As wa11 houses que predominam são assim, desde logo, năo só o símbolo do vórtice temporal em que a vida se desloca sem realmente se mover - mas a representaçăo de uma outra morada, de uma quietude que contém em si, desde logo, o destino dos seus ocupantes. A correspondência que Hejduk estabelece entre a vida e a morte, como dois rostos que se olham mutuamente sem reservas, permite-The conceber uma cidade que, de forma fronta7, condiciona o tempo de uso dos seus espaços e edifícios ao tempo do preenchimento do cemitério; neste sentido, como afirma Peter Eisenman, a cidade constitui-se como uma marca de duplo significado: em primeiro lugar como espaço que consome, morte a morte, a sua própria funcionalidade; em segundo lugar, como rosto de um túmulo, o que significa que a ortodoxia por que se rege a condena, de imediato, a um abandono sim, mas também à eternidade de uma suave deterioração. ["First of a11, it is an idea against consumption because the city is never inhabited again. It is not an object that is worth anything in terms of somebody else reusing it. In these conditions two things happen to 1ife; one is the exhalation of 1ife because your house, your place, your time can never be used again. It is the mark of that existence, so it becomes its own monument. In a certain way it is one's gravestone while one is living. The other thing is that it is also 


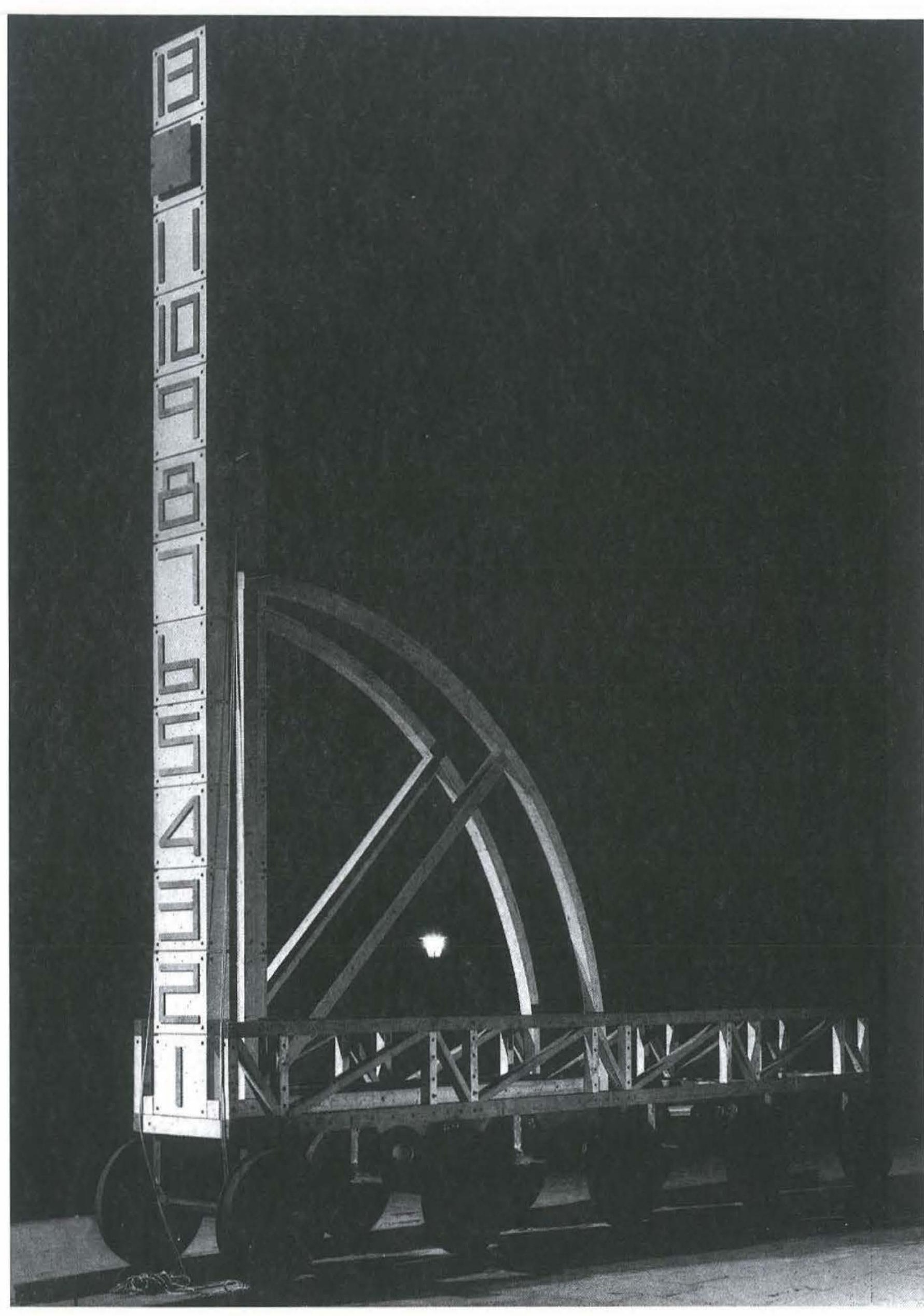


marking your for death; your life is merely marking time, because once you leave your house it becomes your tombstone. So your living in your own tombstone, in a sense."] (11) A afirmaçăo de Eisenman de que a vida na cidade está apenas a marcar o tempo, torna redundante a forma que essa vida possa assumir; é por isso o reconhecimento de uma condição de abandono que não se refere apenas a um deixar para trás de facto - a um afastamento -, mas ao sentir interno de cada um dos seus habitantes, ou seja, à sua submissão a um tempo envolvente e imanente que os preenche e determina. A situação flutuante da cidade, embora localizada geograficamente - It's outside of venice, in the water, afirma Hejduk -, encerra no seu isolamento a postura orguthosa de uma autonomização como somatório ou acumulação de repetidos estados de solidăo que configuram um conjunto igualitário de destinos, tanto no tempo como no espaço. Nesta cidade o destino de cada habitante antecipa-se à sua própria vida, que acontece sob a imanência do primeiro. Em New Town for The New orthodox Hejduk articula a sensualidade de uma metafórica deriva com o terror de um destino que nunca se ausenta do primeiro plano de qualquer das vidas ou dos objectos que aí interagem. Sensualidade e terror são assim transformados em objectos que, como fantasmas com corpo, permanecem firmes e visíveis durante o esvaziamento que irão testemunhar. ["Eisenman: what is striking about the project is the relationship of the house as a marker of life and death. That is the change; what is the house now? what it's symbolic essence is. (...) Death is witnessing life and these people are preparing for death. The living ones are witnessing death as death is witnessing life. It could be better as a New Town for the silent witnesses. New orthodoxy has nothing to do with the solid relationship. These projects are an incredible commentary on death and life in venice and America, on the relations in Europe and the New Society.

$>$ Hejduk: Children are born in The New Town for the New orthodox.

> Eisenman: No, I thought when they close up the house, the idea was that when these 18,000 people died the houses are closed up. I thought as each person dies-

> Hejduk: No, that's too romantic. There's only one thing filling up.

> Eisenman: What happens to the house? People go on living there?

> Hejduk: They're born in them, families live in them.

$>(. .$.

> Eisenman: They live there until the cemetery is full and then what happens to them?

> Hejduk: The town is abandoned when the cemetery is ful1.

> Eisenman: I thought the town gets abandoned progressively?

> Hejduk: No, all at once.] (12)

o facto da cidade não ser abandonada de forma progressiva à medida que as pessoas vão desaparecendo relaciona o momento do derradeiro abandono (quando 
os 18,000 Tugares do cemitério se encontrarem preenchidos na totalidade) com o da parede das wall Houses, no sentido em que o primeiro se poderá constituir como umbral infinito de uma passagem que se transformará num exîlio. Esta é também a condição das pinturas de Edward Hopper, que através dos seus quadros revela uma existência quase resignada à força que o plano do destino exerce; os motivos de Hopper - que aqui devem ser entendidos como personagens, sejam edificios, pessoas ou elementos naturais - expõem-se na tela como naturezas mortas, captadas num instante que se identifica como eternidade. (13) As naturezas mortas de Hopper funcionam assim como ignição de um processo de transformaçăo de uma condiçăo em forma tridimensiona1, com uso (tempo) e espaço. A identificação de Hejduk com o trabalho de Hopper passa assim pela paralisia que neles reconhece como a duraçăo do presente, num estado de abandono relativamente à sua normal sucessão cronológica; aí encontra Hejduk sintomas de uma essencialidade que se representa segundo uma cohabitação entre sensualidade e terror que, como impressão mais do que como evidência, nele se instalam como acção e objectivo. ["John Hejduk: one of the American painters that I find most fascinating at this moment is Edward Hopper. I think Hopper has caught an essenciality - by essenciality I mean 'mood', for want of a better word. Hopper is a really sensous painter, and at the same time what he's about is strangely American. (...) That is, he has caught the dread simoultaneously with the sensousness. The dread, there's a dread in his paintings.

$>$ (..)

> Wa11: when you say dread, you mean...

> Hejduk: Anticipation. 

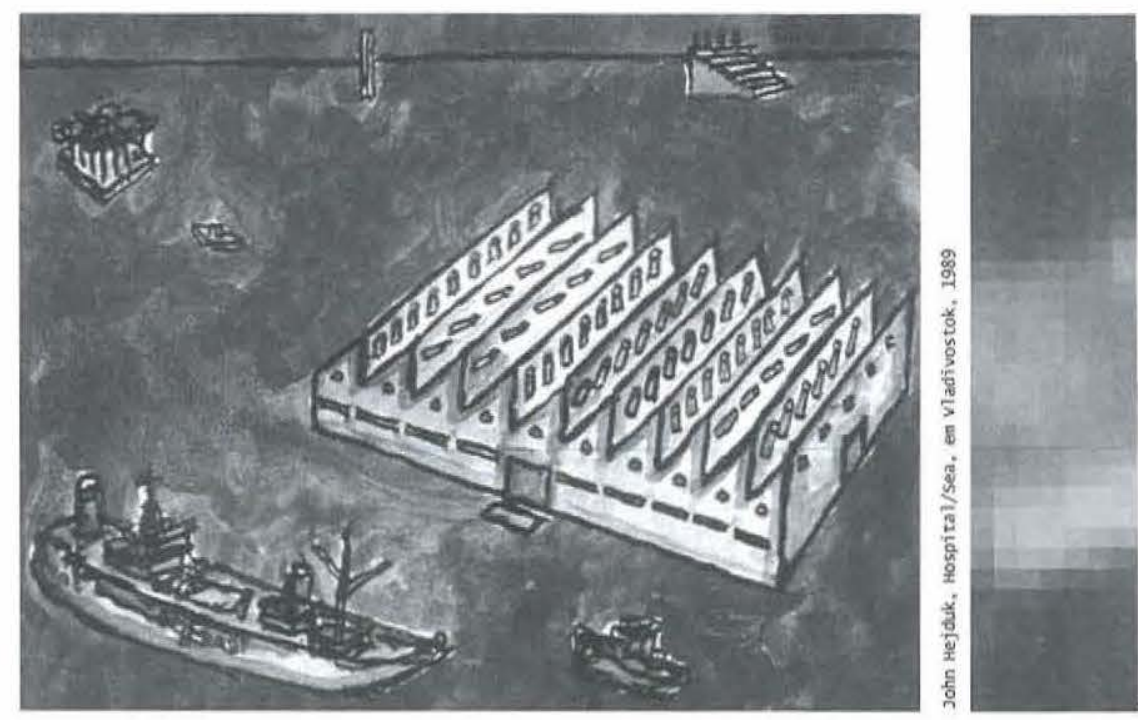

* Wa11: There's anticipation. There is also a barreness to a lot of Hopper's work.

> Hejduk: voidness.

> wa11: Yes. It's void, and yet it is sensous in its voidness. Why the fascination with that?

> Hejduk: With Hopper's paintings? I am intrigued by their combination of pessimism and sensousness.

> wa11: They are abandoned-looking paintings.

> Hejduk: There's abandonment, but they're also, how can I put it? Deceptive paintings."] (14) Em Pensylvania Cowl Town, de Edward Hopper, quase podemos observar o vazio que habita o homem que se encontra a varrer a relva, abandonando-se, literalmente, à sua tarefa. A sua postura, como quem repousa apenas sobre o ar que respira, transmite ao observador uma sensação de ruído nulo externo ao do seu varrer. Entre a calma e sensual luz que o homem recebe frontalmente - como se de uma aparição a que está acostumado se tratasse - e a incredulidade que se possa sentir perante a realidade da cena, ressoa a afirmação de Hejduk de que os quadros de Hopper são falaciosos. Nesse sentido, é possível que a cena retratada năo tenha existido de facto, e seja por isso representada como testemunho da sua própria inexistência. Desta forma Hopper reenvia-nos imagens que são reconhecíveis pelos elementos que contêm, mas que ao mesmo tempo se expõem como criaçăo, isto é, como representação de um imaginário construído com base na observação da interioridade dos objectos, mas que se apresenta sempre para ser visto do exterior. ["Hopper gives us a created world, not one that is merely recorded. 
Everything in it is shaped by memory, sympathy, distance and formal imperatives. Nothing is there merely because it "was there"] (15) A proposta que Hejduk apresenta para o Town Hospital assume-se assim como paradigma máximo de uma provocação à habitual correspondência modernista entre forma e função, transportando para cada elemento da composiçăo significados e funcionalidades que se desviam da sua aparência. De facto, os telescópios amovíveis que Hejduk coloca por cima da cama de cada paciente, podem, na sua posição vertical, assemelhar-se a chaminés; da mesma forma, a repetiçăo do módulo de cobertura que cobre a totalidade da nave, compõe um desenho idêntico ao das coberturas das instalaçöes fabris. Como ponto último, a forma como Hejduk descreve a passagem dos pacientes pelo edifício, como se de um mero atravessamento se tratasse, em tudo se asseme Tha à imagem que podemos fazer de uma linha de montagem. (16) Mas a provocaçăo maior desta proposta é o facto da funcionalidade do edifício nos posicionar frontalmente à realidade objectual do nosso corpo, absolutamente permeável à manipulação -

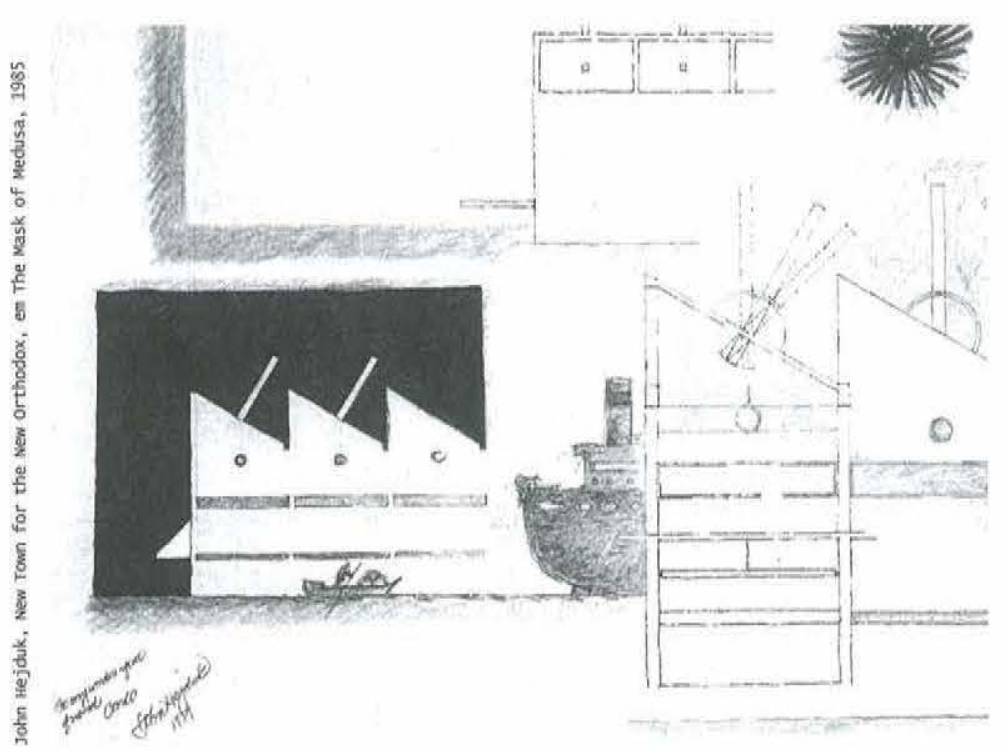

Quase podemos observar o vazio que habita abandonando-se, Titeralmente, à sua tarefa. 
com fins de cura, é certo - mas mesmo assim, analisado, dissecado, transformado. o hospital é, afinal, o espaço onde ocorre essa manipulação, destinada a revelar se, enquanto produto, os corpos que aí entram săo passíveis de renovação ou se, pelo contrário, devem ser despojados. No entanto, num novo golpe de rins, Hejduk sobrepōe ao desconforto e crueldade da imagem desse processo outra que, em convivência próxima com o sofrimento de qualquer doente, o recupera para um estado de suave letargia, aliviando a sua condição de neutro objecto. Nas camas calculadamente situadas por debaixo dos telescópios, qualquer paciente, em convalescença ou em condição de morte eminente, terá a impressäo de se situar defronte a uma janela; no exterior, no entanto, nenhuma referência, apenas o céu, imaginário de profundidade incalculáve1. Deitados nas camas, iludidos pelo movimento dos telescópios, os pacientes podem assim sentir, eles próprios, a ilusão do movimento. Como nos desenhos das wa11 Houses, onde o objecto parece flutuar num espaço sem coordenadas, os corpos dos pacientes do Town Hospital perdem a gravidade que os amarra às camas e à doença, enquanto recuperam a consciência para o exterior dessa condiçăo. A articulação entre o terror e a sensualidade que Hejduk procura a partir dos quadros de Hopper encontra aqui o seu espaço privilegiado; nestes quartos - quadros? - os motivos não săo afinal naturezas mortas (natura morta) mas vidas em suspenso (sti11 1ife), que encerram na sua quietude a consciência de uma duração e a inevitabilidade de um abandono. 0 edifício transforma-se agora num barco, uma nave que, juntamente com os seus pacientes, flutua num espaço macio. os elementos telescópicos, que antes confundíamos com chaminés, são afina1 canhões que projectam sobre o vazio o olhar da memória de cada um dos pacientes.

> Após o preenchimento do cemitério - que, segundo a descrição de Hejduk se assemeTha a uma pirâmide enterrada -, a New Town for the New orthodox é abandonada. o espaço da superfície é liberto da presença fisica dos seus habitantes - dos que morreram e dos que, consequentemente, partiram. o vazio de facto que percorrerá, a partir desse momento, a cidade, funcionará como representação da presença dos seus habitantes.

> Hejduk não nos fala nunca do destino dos sobreviventes. o hospital, contudo, reaparecerá em vladivostok. Terá navegado até ao largo de Riga, local onde, aparentemente, permanece. e c o J 
1 Aldo Rossi, Autobiografia Cientifica, 1998, pág. 9

2 Aldo Rossi, Autobiografía Cientifica, 1998, pág. 63

3 ver Deleuze, Gilles e Guattari, Felix, Treatise on Nomadology - The war Machine e The Smooth and the striated, in A Thousand Plateaus, capitalism and schizophrenia, university of Minnesota Press, Minneapolis, 1987

4 John Hejduk, 'Diary Constructions' en The collapse of Time, 1987

5 John Hejduk, 'Diary constructions', em The collapse of Time, 1987

6 John Hejduk, 'Diary Constructions', em The collapse of Time, 1987

7 Victims, trabalho do inicio dos anos 80 , foi dedicado por Hejduk, simultaneanente as vitimas do holocausto e à cidade de Berlim. Ai săo propostas 67 estruturas de significados diversos que configuram um espaço e uma vivência de resistência poética a un esquecimento que se objectiva como fundamento para - futuro. o local terá albergado câmaras de tortura durante a segunda Guerra Mundial. Security é uma das estruturas propostas por Hejduk (a $n^{\circ} 40$, segundo o catálogo que as apresenta), unidade móvel de patrulha do recinto: Hejduk define-a do seguinte modo: "La Seguridad un vehículo motorizado (eléctrico) que puede moverse por todo el solar. Es decisión de la ciudad de Berlín el que la seguridad se ponga en marcha o no o incluso el que ésta exista.", John Hejduk em victimas, 1993. En 1989 security foi construida pela oslo school of Architecture na praça christiania, onde permaneceu durante treze meses.

Em The collapse of Time, security assume, mais do que un papel de efectiva protecção ou segurança, de testemunha directa da correlatividade entre a experiência da duraçâo (bloqueío do acto presente) imposta pela arquitectura a partir do momento ei que é criada, e a sua vívência como um processo de latente abandono, que, como atmosfera, nos envolve no prenúncio de um inevitável destino. Assim, não ế - espaço/objecto que adquire características temporais, mas, pelo contrário, é o tempo que se revê no objecto e na sua dupla mobilidade como único lugar para uma experiência frontal entre os homens e a efeneridade da sua condiçâa.

8 Platăo, durante a exposiçăo da sua cosmología no Timeu, chega à conclusăo que o tempo é uma imagem da condiçăo eterna do nodelo utilizado para a criaçăo do universo - animal caracterizado por um equitibrio e beleza absolutos - que se adapta à vida do mundo assumindo uma condiçẫo de totalidade segmentada pelo número, †Tusăo de uma progressào que não é mais que o recapitular incessante da eternidade: "Quando o pai que o havia gerado se apercebeu de que o mundo que tinha formado à imagem dos deuses eternos se movia e vivia, ficou encantado e, no seu júbi o, pensou em torná-7o ainda mais semelhante ao seu modelo. ora, como este modelo é um animal eterno, ele esforçou-se por tornar todo este universo também eterno, na medida do possíve1, Mas náo havia maneira de adaptar completamente esta natureza eterna do animal àquilo que é gerado. Entăo, ele lembrou-se de fazer uma imagem nóve 1 da eternidade, ao mesno tempo que organizava o céu, fez da eternidade que resta na unidade esta imagen eterna que progride segundo o número e a que nós chamamos tempo", Platăo, 'Timeu', em Platảo Diálogos IV, 1999, pág. 266

9 John Hejduk, 'Diary Constructions', em The collapse of Time, 1987.

10 John Hejduk, Mask of Medusa, 1985, pág. 85

11 Conversa entre Peter Eisenman e John Hejduk, en Mask of Medusa, 1985, pág. 86

12 conversa entre Peter Eisenman e John Hejduk, em Mask of Medusa, 1985, pág. 86

$13 \mathrm{Em}$ Cemetery for the Ashes of the Still Life painter, proposta incluida em adjusting Foundations, de 1995, John Hejduk estabelece uma relaçäo entre a expressão em inglès stị1 1ife $e$ a expressăo italiana natura morta. o facto de estas duas expressōes, com significados aparentemente opostos se referirem ao mesno tipo de pintura leva Hejduk a considerar que é no acto da representaçāo do objecto ainda en vida que o pintor o transforma em natura morta - "The sarcophagus of the still life is the opaque, 'רife-absorbing' flat canvas. In one move the painter has embalmed a still life into a natura morta. He is the contractor or the undertaker of nature. (..) If the painter could, by a single transformation, take on a three-dimensional still life and paint it on a canvas into a natura morta, could it be possible for the architect to take the natura morta of a painting and, by a single transformation, buil it into a sti11 1ife?", John Hejduk, 'Cemetery for the Ashes of the Still Life Painter', en Adjusting Foundations, 1995, pág. 48

14 Entrevista com Don wall, em Mask of Medusa, 1985, pág. 91

15 Robert Hughes, Under the crack of reality, em unw. arteyclopedia.com

16 when you get sick you enter the Town Hospital in the middle and you either go out to the park or you're put in the Cemetery, John Hejduk, Mask of Medusa, 1985, pág. 84 